\title{
Kerry Blue Terrier
}

National Cancer Institute

\section{Source}

National Cancer Institute. Kerry Blue Terrier. NCI Thesaurus. Code C53723.

The Kerry Blue Terrier is a well-built, muscular, medium-sized dog with true terrier style and character. It has a long head with abundant whiskers, beard and eyebrows. The ears are v-shaped and crease above the skull to fall toward the outside corner of the eye. The coat is black at birth but changes color through one or more transitions. The mature color is from slate blue to light gray. Height: 171/2-20 inches (44-51 cm.) Weight: 33-40 pounds (15-18 kg.) 